mortality among immunocompromised patients with HIV infection or AIDS.

Chorioretinitis is the most common clinical manifestation of infection with CMV in persons with AIDS, followed by gastrointestinal disease. Less common manifestations of CMV include interstitial pneumonitis, subacute encephalitis, polyradiculopathy, and involvement of the adrenal glands, liver and biliary tract.

The first reported case of CMV infection of the prostate involved a 37 year old homosexual man with AIDS who died of disseminated CMV infection. ${ }^{3}$ Pathological examination showed evidence of multiple organ CMV involvement, and prominent invasive CMV infection of the prostate. Our case represents the second reported case of prostatic infection by CMV in a patient with AIDS and, to our knowledge this is the first report of CMV prostatic disease in an intravenous drug abuser. In the report of Miles et al CMV was found at autopsy in the prostate from an AIDS patient who had no clinical signs and symptoms referable to this autoptic finding. ${ }^{3}$

In other surveys which have documented the pathology profiles of AIDS, male genitourinary CMV infection was common, but none presented demonstrable CMV in the prostate. ${ }^{4}$

CMV infection of the prostatic gland can present either as local disease or as part of a systemic infection, although in the case reported by Benson et $a l^{3}$ as in our patient CMV prostatitis appeared as a manifestation of disseminated infection.

However, severe CMV disease of the prostate may occur without the typical features of prostatitis. Thus, the wide range of disease processes observed in patients with AIDS, combined with frequent difficulty of establishing a histologic diagnosis may render the diagnosis obscure, and the selection of the best therapy can be difficult. A possible route for infection includes contiguous infection from surrounding organs, haematogenous or lymphatic spread, or from sexual transmission. For our patient, the mechanism of acquisition of CMV prostatic infection remains undefined.

Several reports support sexual activity as an important role of transmission of CMV infection. Major predisposing conditions for prostatic infection in HIV-positive individuals may include systemic and local immunodeficiency of prostatic tissue and fluid, the presence of concomitant sexually transmitted infections, homosexual practices, and the number of frequency and different sexual partners.

Thus, in addition to subjects engaged in homosexual contacts, subjects with a history of sexually transmitted diseases, and heterosexuals with multiple partners may be at increased risk of becoming CMV infected. CMV is known as an unfrequent cause of genitourinary tract involvement, and diagnosis of prostatitis may be difficult to establish, since patients may be asymptomatic or have, as in our case, nonspecific urinary symptoms.
Although prostatitis due to CMV remains an uncommon clinical entity, the diagnosis of CMV prostatitis require a high degree of clinical suspicion, and should be considered in HIV-positive individuals at risk for invasive CMV infection who present with otherwise unexplained signs and symptoms of genitourinary involvement.

$$
\begin{array}{r}
\text { ANTONIO MASTROIANNI } \\
\text { OLGA CORONADO } \\
\text { ROBERTO MANFREDI } \\
\text { FRANCESCO CHIODO } \\
\text { Departimento di Medicina Clinica, } \\
\text { Specialistica e Sperimentale, } \\
\text { Instituto di Anatomia Patologiaca } \\
\text { Sezione di Malattie Infettive } \\
\text { PAOLO SCARANI } \\
\text { Policlinico Sant'Orsola } \\
\text { Università degli Studi di Bologna } \\
\text { Via Massarenti } 11 \\
\text { 40138 Bologna, Italy. }
\end{array}
$$

Correspondence to: Dr Antonio Mastroianni

1 Miles BJ, Melser M, Farah R, Markowitz N, Fisher E. The urological manifestations of the acquired immunodeficiency syndrome. $\mathcal{F}$ Urol 1989;142:771-3.

2 Stainman VR, Lowe FC. Prostatic disease in HIV-infected patients. The AIDS Reader 1995;5:165-71.

3 Benson PJ, Smith CS. Cytomegalovirus prostatitis. Urology 1992;40:165-7.

4 Reichert CM, O'Learly TJ, Levels DL, Simrell CR Macher AM. Autopsy pathology in the acquired immune deficiency syndrome. Am F Pathol 1983;112:357-82.

Accepted for publication 4 September 1996.

\section{Systemic lupus erythematosus features in an AIDS patient: diagnostic problems in an African rural hospital}

Systemic lupus erythematosus (SLE), as well as other rheumatic diseases, and HIV infection share clinical and laboratory features that can confound the diagnosis especially in hospitals with few laboratory facilities. ${ }^{1}$

We report a case of a 32 year-old woman from Northern Kenya with a clinical picture of SLE and positive agglutination rapid assay for HIV-1. The patient presented with a four months' history of fever, malar rash, loss of body weight, headache and arthralgias together with epigastric pain, urinary incontinence and cough.

Physical examination showed poor nutritional status, erythematous maculo-papular butterfly rash, alopecia, tenderness at knees on active and passive movements and mental confusion. The laboratory findings revealed a leukocyte count $2200 / \mathrm{mm}^{3}$ with $26 \%$ of $1 \mathrm{ym}$ phocytes $\left(572 / \mathrm{mm}^{3}\right)$, ESR $108 \mathrm{~mm} / \mathrm{h}$, haemaglobin $10.0 \mathrm{~g} / \mathrm{dl} ; \mathrm{VDRL}$ and $\mathrm{RF}$ were negative. ANA and anti-DNA antibodies testing were not available in our hospital. Urine was positive $(1+)$ for proteins with few pus cells. Chest radiograph and ECG were normal. Following worsening of mental status a lumbar puncture was performed showing proteins $1+, 6$ leukocytes $/ \mathrm{mm}^{3}$ and glucose $49 \mathrm{mg} / \mathrm{dl}$. Finally the HIV-1 antibodies were tested and found repeatedly positive (twice with the same agglutination rapid assay, Serodia-HIV, Fujirebio Inc).

Although the prevalence of SLE in Kenya is low, ${ }^{2}$ hoping that the HIV-antibody test result could be a false positive due to SLE, a chloro- 
quine treatment ( $300 \mathrm{mg}$ base twice a day) was started and continued for three weeks with no improvement. Subsequently the patient developed chronic diarrhoea and left acute otitis media and the general conditions worsened progressively. She died two months after admission with generalised sepsis, unresponsive to broad spectrum antibiotics, including a trial with intensive antitubercular treatment.

AIDS and SLE diagnosis can interfere with each other in three different ways: (a) AIDS presenting with SLE clinical and serological features, ${ }^{3}$ (b) SLE with false-positive HIV screening tests, ${ }^{145}$ (c) SLE with concomitant AIDS. ${ }^{367}$ Moreover the difficulty in differential diagnosis is increased by the limited diagnostic facilities of an isolated rural hospital.

Although our patient did not fully meet the 1982 ARA revised criteria for the diagnosis of SLE, ${ }^{8}$ the clinical and laboratory features were quite suggestive. Furthermore the hypothesis of SLE autoantibodies producing a false-positive HIV agglutination result opened a therapeutic chance. The most probable diagnosis is AIDS with SLE features. Thus, together with other previous reports, our observation suggests that in high HIV prevalence countries the clinical presentation of SLE could be a marker of AIDS and an indication for HIV testing. F FALASCHI L ANSALONI Sololo General Hospital, PO Box 4, Sololo Moyale District Kenya

Address correspondence to: Dr Luca Ansaloni.

1 Kaye BR. Rheumatologic manifestations of infection with human immunodeficiency virus (HIV). Ann Intern Med 1989;11:158-67.

2 Otieno LS, Wairagu SG, Waweru HW. Systemic lupus erythematosus at Kenyatta National Hospital 1972-1984. E Afr Med $\mathcal{~ 1 9 8 5 ; 6 2 : 3 9 1 - 6 . ~}$

3 Kopelman RG, Zolla-Pazner S. Association of human immunodeficiency virus infection and autoimmune pheimmunodeficiency virus infection and

4 Ranki A, Kurki P, Riepponen S, Stephansson E. Antibodies to retroviral proteins in autoimmune connective tissue disease. Relation to clinical manifestations and ribonucleoprotein autoantibodies. Arthritis Rheum 1992; 35:1483-91

5 Soriano V, Ordi J, Grau J. Tests for HIV in lupus. $N$ Engl $\mathcal{F}$ Med 1994;331:881.

6 Furie R, Kaell A, Petrucci R, Farber B, Kaplan M. Systemic lupus erythematosus (SLE) complicated by infection with human immunodeficiency virus (HIV) Arthritis Rheum 1988;31(suppl 2):S56.

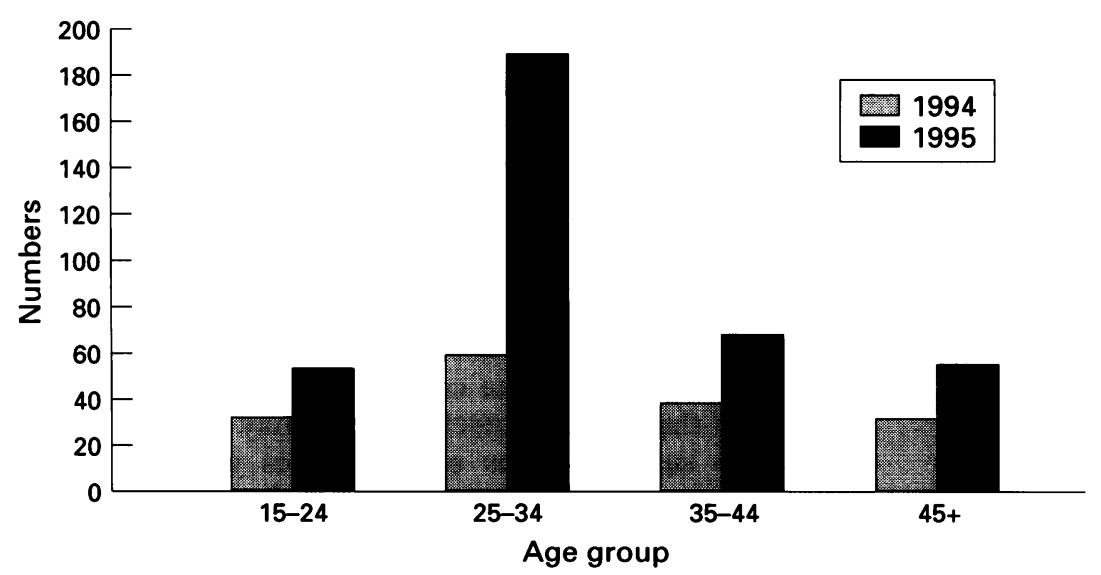

Laboratory reports of Hepatitis A to the Public Health Laboratory Service (PHLS) Communicable Disease Surveillance Centre (CDSC) in the Thames Region 1994-95 in males by age.
7 Povolotsky J, Polsky B, Laurence J, Jindal R, RozonSolomon M, Burrows L. Withdrawal of conclusion: false positive tests for HIV in a woman with lupus. $N$ Engl $\mathcal{F}$ Med 1994;331:881-2.

8 Tan EM, Cohen AS, Fries FJ et al. The 1982 revised criteria for the classification of systemic lupus erythematosus. Arthritis Rheum 1982;25:1271-7.

Accepted for publication 15 August 1996.

\section{Rise in hepatitis $A$ among gay men in the Thames regions 1995 and 1996}

From 1994 to 1995 there was a $73 \%$ (278 to 481 cases) increase in laboratory confirmed Hepatitis A Virus (HAV) infections among adults aged 15 years or over reported to the Public Health Laboratory Service (PHLS) Communicable Disease Surveillance Centre (CDSC) from laboratories in the Thames regions. This was against a background of a $42 \%$ fall in such reports from laboratories in non-Thames regions. The age and sex distribution of reports showed a disproportionate rise (225\%) among men aged 25-34 years (fig). Data in the first 5 months of 1996 suggested that the trend was continuing although levels have reduced in the second half of 1996 . The number reported as homosexual increased by $346 \%$ from 13 to 58 between 1994 and 1995 and there were 23 reports in homosexual men in the first 5 months of 1996.

Reports to consultants in Communicable Disease Control rose markedly in South and East London as well as Brighton and were mainly from general practitioners (GPs) rather than genitourinary medicine clinics. In the boroughs of Tower Hamlets and Hackney during October 1995 to March 1996 reports increased more than fourfold compared with the same period in the previous year and about $40 \%$ were known to be gay. No common exposures (such as functions, foods, contacts, travel or recreational venues) were apparent in investigations carried out in South or East London.

Increased levels of HAV infection among homosexual men in the Thames area have been reported previously in $1980^{1}$ just prior to a national increase in 1981-82, and in $1989^{2}$ during a national increase in 1989-91. This recent increase in the Thames area appears to be in the absence of a national rise.

Transmission of HAV infection is usually faecal-oral. Among homosexuals risk factors include oral-anal contact, ${ }^{3}$ and digital rectal intercourse. ${ }^{4}$

The opportunity presented by the staging of the National Gay Pride Festival in London (6 July 1996) was taken to: (a) deliver public health messages about prevention of HAV infection; and (b) carry out an epidemiological study to determine HAV seroprevalence (using a salivary antibody test) and risk factors for transmission, results of which are currently being analysed.

The co-operation of consultants in genitourinary medicine and GPs in notifying cases of acute HAV infection and facilitating provision of post exposure prophylaxis with human 